\title{
Correction to: Degradation of Uranium-Contaminated Decontamination Film by UV Irradiation and Microbial Biodegradation
}

\author{
Li Zhang ${ }^{2} \cdot$ Jin-long Lai ${ }^{1,3} \cdot$ Yu Zhang ${ }^{2,3} \cdot$ Xue-gang Luo ${ }^{2,3} \cdot$ Zhan-guo Li $^{1}$
}

Published online: 24 January 2022

๑) Springer Science+Business Media, LLC, part of Springer Nature 2022

\section{Correction to: Microbial Ecology}

https://doi.org/10.1007/s00248-021-01862-0

The original article contained error in the order of the affiliations.

Jin-long Lai Contributed equally to this work.

The original article can be found online at https://doi.org/10.1007/ s00248-021-01862-0.

Yu Zhang

1 State Key Laboratory of NBC Protection for Civilian, Beijing 102205, China

2 School of Life Science and Engineering, Southwest University of Science and Technology, Mianyang 621010, China

3 Engineering Research Center of Biomass Materials, Ministry of Education of, SWUST, Mianyang 621010, China 